\title{
What Matters in Colonoscopy?
}

\author{
Hyun Shig Kim \\ Department of Surgery, Seoul Song Do Colorectal Hospital, Seoul, Korea
}

\section{See Article on Page 243-247}

In colonoscopy, time matters. No such way as the so-called 'King's road' exists. Prudent and careful examination, taking sufficient time, is the only way. Nevertheless, an ideal would be to perform a 'complete colonoscopy'. However, even if an excellent colonoscopist does the job, the adenoma miss rate is reportedly $20.9 \%$ [1]. Such clinical misses may be unavoidable in practice. This phenomenon is necessarily connected with interval cancers [2]. These kinds of cancers are considered to be the result of a colonoscopist's failure in spite of his or her efforts. One reason is that the examination is done in an in vivo state in which contractile and propulsive movements of the bowel hindered detailed examination. Another important reason is the existence of blind spots [3]. The colon has innumerable folds and two flexures. These anatomical characteristics cause blind spots that provide hidden places for lesions, such as polyps and cancers. Accordingly endoscopists have to deal with these obstacles.

Sufficient time is the key while doing a colonoscopy. Even if enough time to overcome those above-mentioned hurdles is invested, flat lesions can still be missed $[1,4]$. The colonoscopist must have an adequate understanding of those lesions, and a very careful examination is mandatory. When lesions are found, they must be removed as soon as possible. An on-the-spot removal would be most practical.

Cancer development has various routes [5]. The adenoma-carcinoma sequence is an already well-known mechanism of cancer development. Another, the serrated adenoma-carcinoma pathway has risen to the surface these days. Many believe this pathway to be related to interval cancers, and a cancer originating from a serrated adenoma has already been reported [6], thus making the serrated pathway a top agenda item nowadays. As a clinical en-

Correspondence to: Hyun Shig Kim, M.D.

Department of Surgery, Seoul Song Do Colorectal Hospital, 72 Dasan-ro, Jung-gu, Seoul 100-450, Korea

Tel: +82-2-2250-7368-9, Fax: +82-2-2233-8528

E-mail:mdkhs@hotmail.com

(c) 2013 The Korean Society of Coloproctology

This is an open-access article distributed under the terms of the Creative Commons Attribution NonCommercial License (http://creativecommons.org/licenses/by-nc/3.0) which permits unrestricted noncommercial use, distribution, and reproduction in any medium, provided the original work is properly cited. doscopist, finding serrated lesions, especially sessile-serrated adenomas, is not easy. They are usually flat, pale and easily overlooked. These characteristics are quite different from those of traditional serrated adenomas which are polypoid and easily detected on examination. Sessile-serrated adenomas are usually recognized more in the ascending colon and can be easily missed during colonoscopic procedures.

Other 'de novo' cancers have yet to be defined. Depressed-type cancers are said to be related with 'de novo' cancers. Sometimes accessories such as a hood or a cap may be helpful so as not to overlook lesions in blind spots. In short, time is the key to a complete colonoscopy, so relax, concentrate, and take sufficient time.

\section{REFERENCES}

1. Jung ST, Sohn DK, Hong CW, Kim BC, Park JW, Han KS, et al. Importance of early follow-up colonoscopy in patients at high risk for colorectal polyps. Ann Coloproctol 2013;29:243-7.

2. Kim CJ, Jung YS, Park JH, Kim HJ, Cho YK, Sohn CI, et al. Prevalence, clinicopathologic characteristics, and predictors of interval colorectal cancers in Korean population. Intest Res 2013;11: 178-83.

3. Pickhardt PJ, Nugent PA, Mysliwiec PA, Choi JR, Schindler WR. Location of adenomas missed by optical colonoscopy. Ann Intern Med 2004;141:352-9.

4. Heresbach D, Barrioz T, Lapalus MG, Coumaros D, Bauret P, Potier P, et al. Miss rate for colorectal neoplastic polyps: a prospective multicenter study of back-to-back video colonoscopies. Endoscopy 2008;40:284-90.

5. Takayama T, Takaoka T, Aoki H, Okamoto K. Precursor lesions of colorectal cancers. Gastroenterol Endosc 2013;55:1787-95.

6. Shimodate Y, Takanashi K, Waga E, Fujita T, Katsuki S, Fujita M. Case of early colon cancer in the cecum with mixed serrated polyp (sessile serrated adenoma/polyp and traditional serrated adenoma). Gastroenterol Endosc 2013;55:3409-15. 